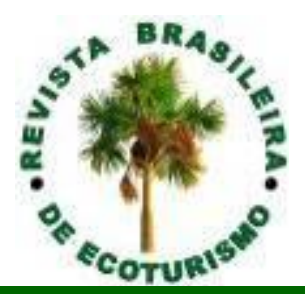

\title{
Avaliação dos Atrativos Turísticos do Parque Nacional de Anavilhanas (AM)
}

\section{Assessment of the Tourist Attractions of the Anavilhanas National Park (AM, Brazil)}

\author{
Mayara de Araujo Silva, Susy Rodrigues Simonetti
}

\begin{abstract}
RESUMO: Esse estudo teve como objetivo avaliar os atrativos turísticos do Parque Nacional de Anavilhanas (AM) por meio de uma matriz, hierarquizando seus atrativos em relação a: infraestrutura, estado de conservação, acesso, grau de uso, apoio local e comunitário, para criar um ranking dos atrativos. Esse estudo de caso se utiliza da metodologia proposta pelo Ministério do Turismo (MTur, 2007) de hierarquização de atrativos turísticos, adaptada para atrativos naturais e, contou ainda com as pesquisas bibliográfica, documental e de campo, e uma oficina para o planejamento participativo com os gestores e operadores que atuam na região do Parque. A partir da análise da hierarquização pode-se construir um ranking dos atrativos do Parque Nacional de Anavilhanas, em uma ordem numérica de acordo com pontuação recebida na avaliação, cujos subsídios auxiliarão na gestão do uso público e no planejamento ecoturístico do Parque. A partir da definição do ranking, percebe-se que há atrativos prioritários como as trilhas terrestres, trilhas aquáticas e o Flutuante dos Botos, para a implementação e a estruturação de ações que visem melhorias para a atividade ecoturística.
\end{abstract}

PALAVRAS-CHAVE: Uso Público; Planejamento e Gestão do Ecoturismo; Áreas Protegidas; Parque Nacional de Anavilhanas.

\section{ABSTRACT}

This study aimed to evaluate the tourist attractions of the Anavilhanas National Park (AM, Brazil) through a matrix, hierarchizing its attractions in relation to: infrastructure, state of conservation, access, degree of use, local and community support, to create a ranking of the attractions. This case study is based on the methodology proposed by the Ministry of Tourism (MTur, 2007) for the hierarchization of tourist attractions, adapted to natural attractions, as well as bibliographical, documentary and field research, and a workshop for participatory planning with the managers and operators that work in the region of the Park. From the hierarchy analysis, one can construct a ranking of the attractions of the Anavilhanas National Park, in numerical order according to the score received in the assessment, whose subsidies will aid in the management of public use and in the ecotourism planning of the Park. From the definition of the ranking, it is noticed that there are priority attractions such as the walking trails, the aquatic trails and the River Dolphins Floating, for the implementation and structuring of actions that aim at improvements for the ecotourism activity.

KEYWORDS: Public Use; Planning and Management of Ecotourism; Protected Areas; Anavilhanas National Park. 


\title{
Introdução
}

Uma das principais Unidades de Conservação (UCs) federais, situada no estado do Amazonas, que permite atividades de observação e interação com fauna silvestre em seu interior é o Parque Nacional de Anavilhanas, como destaca Vidal (2018). Nos últimos anos a área protegida vem ganhando destaque na política de estruturação, planejamento e fomento ao desenvolvimento turístico promovido pelo Ministério do Turismo, em parceria com o Ministério do Meio Ambiente (IPE, 2009).

O Parque Nacional de Anavilhanas (Parna), área protegida instituída pela Lei $n^{\circ} 11.799$, de 29 de outubro de 2008, localizado em Novo Airão, município do estado do Amazonas, distante da capital Manaus $200 \mathrm{~km}$ por via terrestre, está entre os destinos naturais mais procurados por visitantes que buscam conhecer suas belezas e atrativos associados ao lazer e bemestar, proporcionado pelo ambiente natural preservado das muitas ilhas que formam o arquipélago.

O Parque está localizado nos municípios de Novo Airão $(70,5 \%)$ e Manaus (29,5\%), no estado do Amazonas, totalizando uma área de 3.504,70 $\mathrm{km}^{2}$ ou 350.469,79 ha. O Parna localiza-se no rio Negro, cerca de $40 \mathrm{~km}$ por via aquática acima da cidade de Manaus (ICMBIO, 2017).

De acordo com Plano de Manejo do Parque Nacional de Anavilhanas (ICMBio, 2017, p. 243), o objetivo da UC é:

\begin{abstract}
preservar o arquipélago fluvial de Anavilhanas bem como suas diversas formações florestais, além de estimular a produção de conhecimento por meio da pesquisa científica e valorizar a conservação do bioma Amazônia com base em ações de educação ambiental e turismo sustentável. O foco é harmonizar as relações entre as comunidades do entorno e a Unidade com ações de bases sustentáveis.
\end{abstract}

O segundo maior arquipélago fluvial do mundo, o arquipélago de Anavilhanas, localiza-se nos limites do Parna, com aproximadamente 400 ilhas e 60 lagos, além de inúmeros paranás e furos (Figura 1). $O$ acesso ao Parque ocorre por vias fluvial, terrestre ou aérea, esta última por meio de hidroavião ou helicóptero (não há aeroporto).

As principais atividades do Parque incluem a interação com botos vermelhos (Inia geoffrensis), trilhas aquáticas, atividades náuticas, visita às praias, trilhas terrestres, voo panorâmico, escalada em árvores, pernoite em praias, observação de fauna, flora e paisagem.

Pesquisas realizadas no Parque Nacional de Anavilhanas, relacionadas ao perfil dos visitantes, apontaram que os brasileiros são os principais visitantes do Parque, sendo a maioria do próprio estado do Amazonas. Esse fato pode ser atribuído, em parte, ao menor custo e tempo de deslocamento por visitantes que moram em cidades próximas, como Manaus, Manacapuru e Iranduba, todas situadas em um raio de até $200 \mathrm{~km}$ por via terrestre do Parque (VIDAL et al., 2013). 


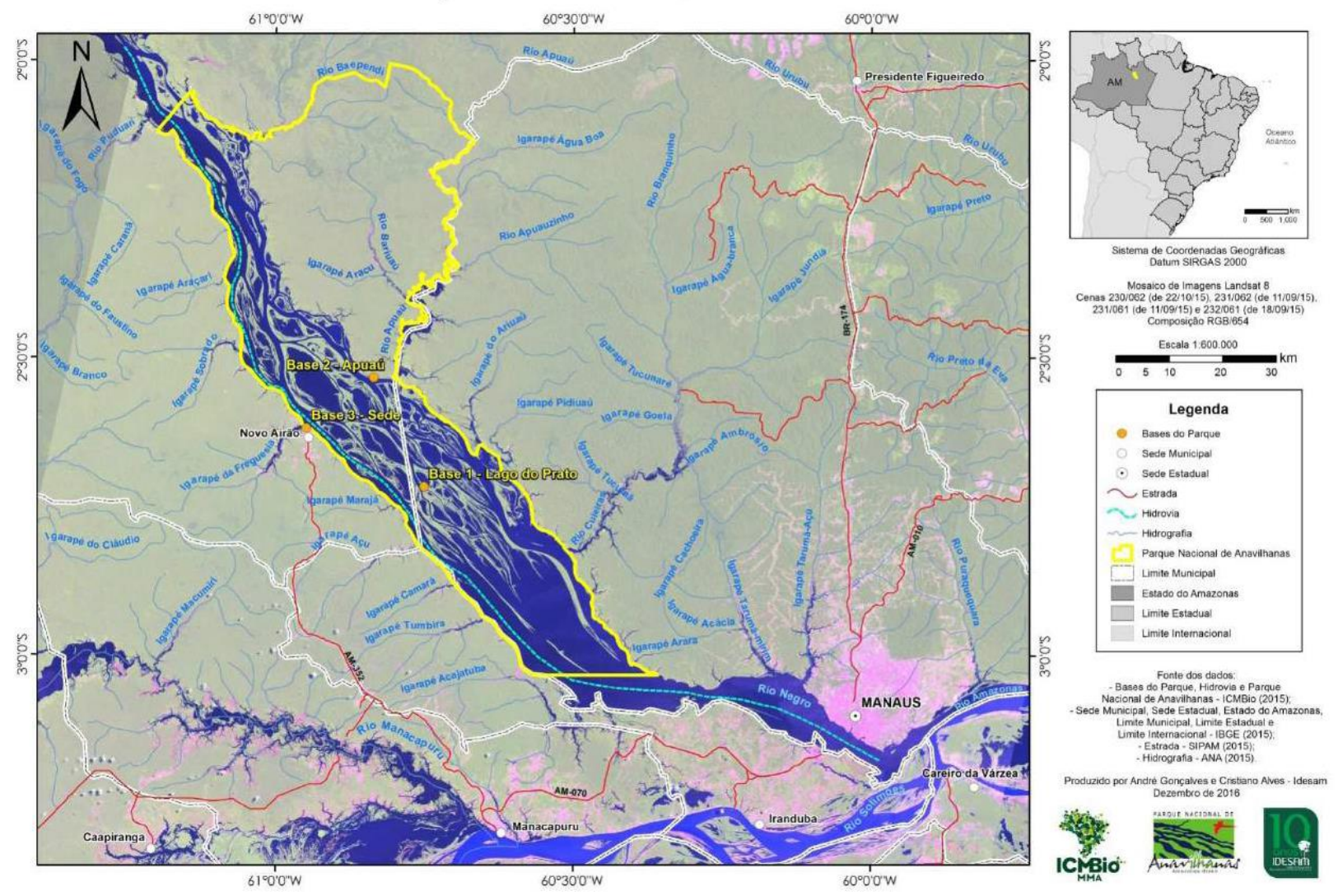

Figura 1: Mapa do Parque Nacional de Anavilhanas. Fonte: ICMBio (2017).

Figure 1: Map of Anavilhanas National Park. Source: ICMBio (2017).

É importante observar que a maioria dos visitantes faz parte do que se considera turismo doméstico. Os turistas internacionais que visitam o Parque são dos Estados Unidos, Suíça, Alemanha e Itália. Os demais visitantes são oriundos de outros países da Europa, América Latina, Caribe. Há ainda em menor número, registro de estrangeiros de países como Índia, Singapura, Taiwan, Israel e Nova Zelândia. A maioria dos visitantes possui nível superior e realiza atividades correlacionadas ao ecoturismo, como observação de mamíferos (botos), banhos e passeios de canoa (SIMONETTI et al., 2017).

Na perspectiva do ecoturismo em áreas protegidas e como ferramenta de gestão, surge a seguinte indagação: quais dos atrativos do Parque Nacional de Anavilhanas possuem efetivamente potencial de atratividade turística?

Nesse sentido, a contribuição desse trabalho será para preencher uma lacuna, pois não há trabalhos científicos que se utilizem da matriz de avaliação e hierarquização de atrativos no Parque que sirvam de apoio à gestão. Esse trabalho se propôs a fornecer subsídio para ajudar no planejamento ecoturístico do Parque, sendo esta uma das justificativas do estudo.

Com base nesse contexto, o estudo tem como objetivo avaliar os atrativos turísticos do Parque Nacional de Anavilhanas, por meio de uma matriz de avaliação, hierarquizando seus atrativos em relação a: 
infraestrutura, estado de conservação, acesso, grau de uso e apoio local comunitário.

O presente estudo utilizou uma metodologia de hierarquização, que auxilia na avaliação da importância dos atrativos identificados para possível inclusão em roteiros de visitação. A hierarquização dos atrativos turísticos do Parque serve de subsídio e instrumento de planejamento e gestão para ajudar a estabelecer prioridades que determinam a escolha e a tomada de decisão estratégica de governantes, administradores, gestores e empreendedores, no que se refere ao uso público da área protegida, bem como, aos projetos e à infraestrutura a eles associada.

\section{Referencial teórico}

O processo de avaliação de atrativos busca fornecer informações para que se possa ordenar o grau de importância que cada atrativo representa, criando um ranking. Os resultados desse processo devem auxiliar no planejamento de visitação e fornecer subsídios para identificar quais atrativos requerem atenção ou quais são os mais procurados pela demanda turística.

Os autores relacionados ao tema dessa pesquisa (atrativos turísticos e hierarquização de atrativos), reafirmam a necessidade de mais estudos de avaliação de atrativos turísticos, e afirmam que poucos foram aqueles que avançaram em direção à construção de referenciais para tal análise (INSKEEP, 1991; LENO CERRO, 1993; BOULLÓN, 1995; PINZAN, 2003; IGNARRA, 2003). Sendo assim, tal literatura ainda pode ser considerada escassa ou insuficiente.

Almeida (2009) apresenta alguns referenciais teóricos consagrados que se destacaram ao longo da pesquisa sobre o tema de hierarquização e matriz de avaliação de atrativos turísticos, cujas principais considerações estão relacionadas no Quadro 1, a seguir:

Quadro 1 - Principais características dos referenciais teóricos identificados:

Table 1 - Main characteristics of the identified theoretical frameworks:

\begin{tabular}{|c|l|}
\hline Referenciais Teóricos & \multicolumn{1}{|c|}{ Principais Características } \\
\hline \multirow{2}{|c|}{$\begin{array}{c}\text { Índice de Atratividade Turística de } \\
\text { Gearing, Swart e Var ou Tourist } \\
\text { Attraction Index (TAI) (Fagliari e }\end{array}$} & $\begin{array}{l}\text { Método indireto de preferência dos usuários (a } \\
\text { partir de pesquisa com especialistas, que devem } \\
\text { ser cuidadosamente escolhidos); Foco nos } \\
\text { atrativos turísticos; Utilização de pesos e escalas } \\
\text { numéricas para as avaliações; Aparente } \\
\text { simplicidade e maleabilidade quanto ao uso. }\end{array}$ \\
\hline \multirow{2}{*}{$\begin{array}{l}\text { Área de estudo: Região Metropolitana da Baixada } \\
\text { Santista/SP/Brasil; Uso de fórmulas matemáticas; } \\
\text { (2003) }\end{array}$} & $\begin{array}{l}\text { Análise baseada em um tipo específico de } \\
\text { atrativo turístico (praia) e na estrutura de } \\
\text { hospedagem. }\end{array}$ \\
\hline
\end{tabular}

Continua... 
...continuacão.

\begin{tabular}{|c|c|}
\hline Referenciais Teóricos & Principais Características \\
\hline $\begin{array}{l}\text { Ferramenta para Determinação do } \\
\text { Potencial Turístico de Casal (2002) }\end{array}$ & $\begin{array}{l}\text { Utilizada para o planejamento do turismo } \\
\text { alternativo (foco da obra de Casal), mais } \\
\text { especificamente para o planejamento e desenho } \\
\text { de serviços alternativos; Inicia-se a partir do } \\
\text { inventário da oferta turística; Aparentemente não } \\
\text { mostra nenhuma preocupação com o sistema de } \\
\text { pontuação ou com qualquer outro indicador de } \\
\text { avaliação, além de apresentar aspectos } \\
\text { questionáveis do ponto de vista da subjetividade } \\
\text { em sua lista de considerações sobre os atrativos. }\end{array}$ \\
\hline $\begin{array}{l}\text { Matriz de Avaliação de Atrações } \\
\text { Turísticas de Inskeep (1991) }\end{array}$ & $\begin{array}{l}\text { Deve considerar a experiência e o julgamento da } \\
\text { equipe de planejamento; Aspectos considerados: } \\
\text { características naturais dos atrativos turísticos, } \\
\text { características culturais e características } \\
\text { especiais (podem variar de acordo com a área a } \\
\text { ser avaliada); Fatores de avaliação: } \\
\text { acessibilidade, factibilidade econômica do } \\
\text { desenvolvimento, impactos ambientais e } \\
\text { socioculturais do desenvolvimento, e importância } \\
\text { nacional, regional e internacional das atrações; } \\
\text { Utilização de escala numérica para avaliação. }\end{array}$ \\
\hline $\begin{array}{c}\text { Adaptação da Metodologia de } \\
\text { Hierarquização de Recursos Turísticos } \\
\text { da OEA para Aplicação na Comunidade } \\
\text { Autônoma de La Rioja por Alvarez } \\
\text { Cuervo e Leno Cerro (LENO CERRO, } \\
\text { 1993) }\end{array}$ & $\begin{array}{l}\text { Área de estudo: Comunidade Autônoma de } \\
\text { La Rioja/Espanha; Uso de fórmulas matemáticas; } \\
\text { Introdução de um fator de ponderação relativo à } \\
\text { zona em que se localiza o recurso (que corrige a } \\
\text { hierarquia inicial outorgada ao recurso) e de três } \\
\text { elementos considerados importantes pelos } \\
\text { autores: a conectividade (acessibilidade física), a } \\
\text { concentração de recursos e a oferta de } \\
\text { alojamento e restauração. }\end{array}$ \\
\hline $\begin{array}{c}\text { Avaliação dos Recursos Turísticos da } \\
\text { OMT (LENO CERRO, 1993) }\end{array}$ & $\begin{array}{l}\text { Estabelecimento de duas grandes categorias: } \\
\text { fatores internos (grau de utilização do recurso: } \\
\text { urbanização, infraestrutura e equipamentos e } \\
\text { serviços turísticos; e características intrínsecas) e } \\
\text { fatores externos (acessibilidade, proximidade a } \\
\text { centros emissores, especificidade do recurso e } \\
\text { importância do } \\
\text { recurso); Uso de fórmulas matemáticas; Objetivo } \\
\text { principal: determinar o valor de diversas zonas } \\
\text { com o fim de estabelecer uma ordem de } \\
\text { prioridade nos trabalhos de planejamento e } \\
\text { desenvolvimento do turismo. }\end{array}$ \\
\hline
\end{tabular}

Fonte: Adaptado de Almeida (2009, pp. 544-547).

Source: Adapted from Almeida (2009, pp. 544-547).

Os atrativos naturais, no contexto desse estudo, são os elementos de destaque do produto turístico no Parque Nacional, por serem um dos que mais provocam o aumento de concentração de turistas ou de serviços turísticos locais em seu entorno. Eles requerem qualidade do meio ambiente, zelo pelos recursos naturais e pelas comunidades receptoras. Nessa perspectiva "[...] o turismo pode ser estimulado não só como um meio de conhecimento, mas, também, como um modo de transmitir uma imagem favorável ao visitante [...]" (IGNARRA, 2013, p. 192). 
Segundo o Ministério do Turismo (MTur, 2017), o Brasil é apontado como o número um em recursos naturais entre 136 países analisados, rico em biodiversidade, reservas de água doce, litoral extenso e florestas preservadas. E, suas belezas naturais, associadas ao lazer, atraem tanto turistas estrangeiros quanto brasileiros interessados em conhecer cada vez mais o país.

O tema é tão importante que 2017 foi eleito, pela Organização Mundial do Turismo (OMT), como o Ano Internacional do Turismo Sustentável para o Desenvolvimento. Considerado o país número um em atrativos naturais, segundo o Relatório de Competitividade do Turismo do Fórum Econômico Mundial - FEM de 2017, o Brasil ainda aproveita pouco do seu potencial turístico, principalmente em relação às áreas de rios, lagos, costa marítima e fortes (BRASIL, 2017).

Dados expressivos assim levam à reflexão sobre o fenômeno turístico, foco de discussões das diversas nações em todo o planeta, pelo fato de, gradativamente, as sociedades estarem exercendo maior pressão sobre os ambientes naturais em decorrência da sua popularização.

Os atrativos são a base sobre a qual deve se fundamentar qualquer plano de desenvolvimento turístico, dessa forma, seu inventário e avaliação são fundamentais para o processo de planejamento. A avaliação dos atrativos e recursos determina seu potencial e, consequentemente, implica no potencial turístico da localidade. Sendo assim, tal avaliação é essencial para a tomada de decisões estratégicas, pois fornece subsídios para determinar a abrangência dos projetos e a quantidade e a qualidade dos equipamentos e da infraestrutura que devem ser instaladas (RUSCHMANN, 1997).

Para a avaliação dos atrativos é recomendável estabelecer uma hierarquização de atratividade. O modelo mais conhecido é o proposto pelo antigo Centro de Capacitação para o Turismo da Organização dos Estados Americanos - CICATUR. Grande parte das metodologias existentes para avaliação de atrativos é baseada no modelo do CICATUR. Porém, a metodologia de hierarquização de atrativos turísticos no Brasil mais recente é a utilizada pelo Ministério do Turismo (MTur, 2007), adaptada da Organização Mundial do Turismo (OMT).

De acordo com o MTur (2007, p. 46-47), a aplicação dessa metodologia tem como objetivo:

auxiliar na avaliação da importância dos atrativos identificados para inclusão no roteiro turístico. [...] Avaliamse aspectos que auxiliarão na definição dessa hierarquia. [...] Deste modo, fornece subsídios para a diferenciação objetiva das características e dos graus de importância de cada atrativo. Esse critério permite classificar cada atrativo de acordo com uma escala preestabelecida. pautado.

É com base na metodologia do MTur (2007) que este estudo está 


\section{Materiais e métodos}

Esse estudo de caso se utilizou da metodologia proposta pelo Ministério do Turismo (MTur, 2007) de hierarquização de atrativos turísticos, adaptada para atrativos naturais, com instrumentos e técnicas aplicadas como: questionário, uma oficina participativa e observação, e, contou ainda com as pesquisas: de campo, bibliográfica e documental.

\section{Pesquisa bibliográfica e documental}

Para este estudo fez-se necessário a consulta documental e bibliográfica em livros, artigos científicos, teses e dissertações, documentos qualificados e ligados ao tema de hierarquização de atrativos. Utilizou-se ainda o Plano de Manejo do Parque Nacional de Anavilhanas (2017) apoiado no inventário, na identificação e avaliação dos atrativos.

\section{Pesquisa de campo}

A pesquisa de campo atendeu aos objetivos da coleta de dados e contou ainda com instrumentos e técnicas aplicadas como: questionário, uma oficina participativa e observação sistemática e assistemática durante as visitas aos atrativos do Parque.

\section{- Questionários}

O questionário com perguntas semiestruturadas (roteiro préestabelecido), fora com o intuito de coletar dados a respeito da prática da atividade de visitação no Parque, informações sobre os atrativos e prestação de serviços turísticos, foram realizados com os atores sociais afetados direta e indiretamente pela atividade de visitação no Parque Nacional de Anavilhanas nos meses de agosto e setembro de 2018, e tiveram a duração de 35 mim cada.

A quantidade de questionários podem ser assim resumidos (Quadro 2):

Quadro 2: Número de questionários individuais aplicados.

Table 2: Number of individual questionnaires applied.

\begin{tabular}{|l|c|}
\hline \multicolumn{1}{|c|}{ Atores Sociais } & $\begin{array}{c}\text { Questionários } \\
\text { Individuais }\end{array}$ \\
\hline Representante do ICMBio (órgão gestor do parque) & 1 \\
\hline $\begin{array}{l}\text { Guias/condutores de turismo da Associação de Operadores de Turismo de } \\
\text { Novo Airão - ATUNA }\end{array}$ & 13 \\
\hline Representante da Secretaria de Meio Ambiente de Novo Airão - SEMMA & 1 \\
\hline $\begin{array}{l}\text { Representante da Secretaria Municipal de Turismo de Novo Airão - } \\
\text { SEMTUR }\end{array}$ & 1 \\
\hline Empresas operadoras de turismo e de passeios turísticos & 1 \\
\hline Hotéis e pousadas & 3 \\
\hline TOTAL DE QUESTIONÁRIOS & 20 \\
\hline
\end{tabular}

Fonte: Pesquisa de campo, 2018.

Source: Field research, 2018. 


\section{- Oficina Participativa}

A oficina participativa, com os atores sociais envolvidos e apresentados anteriormente, foi realiza no dia 10 de outubro de 2018, no município de Novo Airão, na Escola Estadual de Tempo Integral Balbina Mestrinho e teve duração de 4 horas.

A oficina objetivou coletar informações, identificar os atrativos do Parque Nacional de Anavilhanas e fazer a hierarquização desses atrativos em relação a: infraestrutura, estado de conservação, grau de uso, acesso e apoio local comunitário.

Para essa oficina foi utilizada como base a Metodologia de Hierarquização dos Atrativos Turísticos proposta pelo Ministério do Turismo, adaptada a partir da sugestão da Organização Mundial do Turismo (OMT) e pelo Centro Interamericano de Capacitação Turística (CICATUR), que para esse estudo foi direcionada somente para atrativos naturais. A aplicação dessa metodologia teve como objetivo principal avaliar o grau de importância dos atrativos identificados para possível inclusão em roteiro turístico.

No Quadro 3 estão apresentados os critérios citados para a hierarquização dos atrativos, definidos da seguinte forma:

Quadro 3: Características dos critérios para a avaliação dos atrativos turísticos.

Table 3: Characteristics of the criteria for the evaluation of tourist attractive.

\begin{tabular}{|c|l|}
\hline ITENS DE AVALIAÇÃO & \multicolumn{1}{|c|}{ CARACTERÍSTICAS } \\
\hline Infraestrutura & $\begin{array}{l}\text { Busca-se, por meio do estudo in loco, verificar a existência } \\
\text { de infraestrutura turística disponível no atrativo e seu } \\
\text { estado de conservação; }\end{array}$ \\
\hline $\begin{array}{l}\text { Estado de conservação da } \\
\text { paisagem circundante }\end{array}$ & $\begin{array}{l}\text { Busca-se verificar, por meio do estudo de campo, a } \\
\text { ambiência do atrativo e avaliar o estado de conservação } \\
\text { da sua paisagem circundante; }\end{array}$ \\
\hline Grau de uso atual & $\begin{array}{l}\text { Permite analisar o atual volume de fluxo turístico efetivo e } \\
\text { a importância que adquire frente ao Parque. Difere do } \\
\text { grau de interesse por representar a situação vigente e não } \\
\text { um potencial; }\end{array}$ \\
\hline Acesso & $\begin{array}{l}\text { Busca-se verificar a existência e condições de uso das } \\
\text { vias de acesso ao atrativo. Deve-se levar em } \\
\text { consideração a distância e o custo para chegar até o } \\
\text { atrativo. }\end{array}$ \\
\hline Apoio local comunitário & $\begin{array}{l}\text { Busca-se avaliar o grau de interesse da comunidade local } \\
\text { no atrativo em relação ao uso turístico; }\end{array}$ \\
\hline
\end{tabular}

Fonte: Adaptado de MTUR, 2007.

Source: Adapted from MTUR, 2007.

Posteriormente, foram avaliados os aspectos que definem a hierarquia, o que permitiu classificar cada atrativo de acordo com uma escala preestabelecida de valores (Quadro 4). 
Quadro 4: Critérios para a avaliação dos atrativos turísticos.

Table 4: Criteria for the evaluation of tourist attractive.

\begin{tabular}{|c|c|c|c|c|c|}
\hline & \multirow{2}{*}{ Critérios } & \multicolumn{4}{|c|}{ Valores } \\
\hline & & 0 & 1 & 2 & 3 \\
\hline \multirow{5}{*}{ 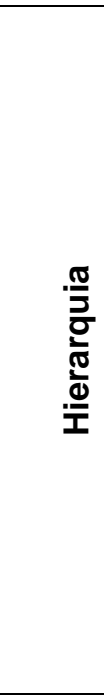 } & Infraestrutura & Inexistente & $\begin{array}{l}\text { Existe, porém } \\
\text { em estado } \\
\text { precário }\end{array}$ & $\begin{array}{c}\text { Existe, mas } \\
\text { necessita de } \\
\text { intervenções/ } \\
\text { melhorias }\end{array}$ & $\begin{array}{l}\text { Existente e } \\
\text { em ótimas } \\
\text { condições }\end{array}$ \\
\hline & $\begin{array}{l}\text { Estado de conservação } \\
\text { da paisagem } \\
\text { circundante }\end{array}$ & $\begin{array}{l}\text { Estado de } \\
\text { conservação } \\
\text { péssimo }\end{array}$ & $\begin{array}{c}\text { Estado de } \\
\text { conservação } \\
\text { regular }\end{array}$ & $\begin{array}{c}\text { Bom estado } \\
\text { de } \\
\text { conservação }\end{array}$ & $\begin{array}{c}\text { Ótimo } \\
\text { estado de } \\
\text { conservação }\end{array}$ \\
\hline & Grau de uso atual & $\begin{array}{c}\text { Fluxo } \\
\text { turístico } \\
\text { insignificante }\end{array}$ & $\begin{array}{l}\text { Pequeno } \\
\text { Fluxo }\end{array}$ & $\begin{array}{c}\text { Média } \\
\text { intensidade de } \\
\text { fluxo }\end{array}$ & Grande fluxo \\
\hline & Acesso & Inexistente & $\begin{array}{c}\text { Em estado } \\
\text { precário }\end{array}$ & $\begin{array}{c}\text { Necessita de } \\
\text { intervenções/ } \\
\text { melhorias } \\
\end{array}$ & $\begin{array}{l}\text { Em ótimas } \\
\text { condições }\end{array}$ \\
\hline & Apoio local comunitário & Nenhum & $\begin{array}{c}\text { Apoio de uma } \\
\text { pequena parte } \\
\text { da } \\
\text { comunidade }\end{array}$ & Apoio razoável & $\begin{array}{c}\text { Apoio de } \\
\text { grande parte } \\
\text { da } \\
\text { comunidade }\end{array}$ \\
\hline Total & & & & & \\
\hline
\end{tabular}

Fonte: Adaptado do Programa de Regionalização do Turismo - Roteiros do Brasil (MTUR, 2007).

Source: Adapted from the Program of Regionalization of Tourism - Circuits from Brazil (MTUR, 2007).

Após o conhecimento desses critérios foi possível hierarquizar os atrativos. A hierarquização foi estabelecida da seguinte forma: cada atrativo inventariado foi analisado separadamente, ou seja, cada atrativo foi avaliado individualmente, estabelecendo assim sua hierarquia.

Os participantes da oficina, por conhecerem e atuarem diariamente na região do Parque, identificaram e avaliaram os atrativos de acordo com os critérios do Quadro 4, recebendo uma pontuação para cada critério avaliado, em seguida os pontos obtidos foram somados.

A identificação e a hierarquização dos atrativos do Parque realizadas durante a oficina são apresentadas no Quadro 5:

Quadro 5: Hierarquização dos atrativos do Parque Nacional de Anavilhanas.

Table 5: Hierarchy of the attractive of the Anavilhanas National Park.

\begin{tabular}{|c|c|c|c|c|c|c|c|}
\hline \multirow[b]{2}{*}{ № } & \multirow[b]{2}{*}{$\begin{array}{l}\text { ATRATIVOS DO PARQUE } \\
\text { NACIONAL DE ANAVILHANAS }\end{array}$} & \multicolumn{5}{|c|}{ CRITÉRIOS PARA A AVALIAÇÃO DOS ATRATIVOS } & \multirow[b]{2}{*}{$\begin{array}{c}\text { Total } \\
\text { de } \\
\text { pontos }\end{array}$} \\
\hline & & $\begin{array}{l}\text { Infraestru- } \\
\text { tura }\end{array}$ & $\begin{array}{c}\text { Estado de } \\
\text { conservação } \\
\text { da paisagem } \\
\text { circundante }\end{array}$ & Acesso & $\begin{array}{c}\text { Grau } \\
\text { de } \\
\text { uso } \\
\text { atual }\end{array}$ & $\begin{array}{l}\text { Apoio } \\
\text { local } \\
\text { comuni } \\
\text {-tário }\end{array}$ & \\
\hline 1 & Trilha terrestre do Apuaú & 2 & 2 & 2 & 1 & - & 7 \\
\hline 2 & Trilha terrestre do Andorinha & 0 & 2 & 3 & 2 & - & 7 \\
\hline 3 & Trilha terrestre do Tamuatá & 0 & 2 & 3 & 2 & - & 7 \\
\hline 4 & Trilha terrestre do Miritipuca & 0 & 3 & 1 & 0 & - & 4 \\
\hline 5 & Trilha terrestre do Barro Branco & 0 & 3 & 1 & 0 & - & 4 \\
\hline 6 & Trilha terrestre do Bariaú & 0 & 3 & 0 & 0 & - & 3 \\
\hline 7 & Trilha terrestre do Apacuzinho & 0 & 2 & 3 & 1 & - & 6 \\
\hline
\end{tabular}


...continuação.

\begin{tabular}{|c|c|c|c|c|c|c|c|}
\hline \multirow[b]{2}{*}{ № } & \multirow[b]{2}{*}{$\begin{array}{l}\text { ATRATIVOS DO PARQUE } \\
\text { NACIONAL DE ANAVILHANAS }\end{array}$} & \multicolumn{5}{|c|}{ CRITÉRIOS PARA A AVALIAÇÃO DOS ATRATIVOS } & \multirow[b]{2}{*}{$\begin{array}{c}\text { Total } \\
\text { de } \\
\text { pontos }\end{array}$} \\
\hline & & $\begin{array}{l}\text { Infraestru- } \\
\text { tura }\end{array}$ & $\begin{array}{c}\text { Estado de } \\
\text { conservação } \\
\text { da paisagem } \\
\text { circundante }\end{array}$ & Acesso & $\begin{array}{l}\text { Grau } \\
\text { de } \\
\text { uso } \\
\text { atual }\end{array}$ & $\begin{array}{l}\text { Apoio } \\
\text { local } \\
\text { comuni } \\
\text {-tário }\end{array}$ & \\
\hline 8 & Furo do Andorinha (trilha aquática) & 0 & 2 & 2 & 3 & - & 7 \\
\hline 9 & Furo do Tamuatá (trilha aquática) & 0 & 1 & 3 & 3 & - & 7 \\
\hline 10 & Furo do Mosquito (trilha aquática) & 0 & 1 & 3 & 3 & - & 7 \\
\hline 11 & Lago do Canauiri (trilha aquática) & 0 & 1 & 3 & 3 & - & 7 \\
\hline 12 & $\begin{array}{l}\text { Paraná do Pavão Comprido (trilha } \\
\text { aquática) }\end{array}$ & 0 & 1 & 3 & 3 & - & 7 \\
\hline 13 & Furo do Arraia (trilha aquática) & 0 & 2 & 3 & 3 & - & 8 \\
\hline 14 & Furo do Apuí (trilha aquática) & 0 & 1 & 3 & 3 & - & 7 \\
\hline 15 & $\begin{array}{l}\text { Furo do Apacuzinho (trilha } \\
\text { aquática) }\end{array}$ & 0 & 3 & 3 & 1 & - & 7 \\
\hline 16 & $\begin{array}{l}\text { Lago do Barro Branco (trilha } \\
\text { aquática) }\end{array}$ & 0 & 3 & 1 & 0 & - & 4 \\
\hline 17 & Lago do Marajá (trilha aquática) & 0 & 2 & 2 & 0 & 2 & 6 \\
\hline 18 & Praia do Camaleão & 0 & 1 & 2 & 2 & - & 5 \\
\hline 19 & Praia do Folharal & 0 & 1 & 3 & 2 & - & 6 \\
\hline 20 & Praia do Saracá & 0 & 0 & 3 & 2 & 1 & 6 \\
\hline 21 & Praia da Orla de Novo Airão & 0 & 0 & 3 & 3 & 2 & 8 \\
\hline 22 & Praia do Meio (praia do Miritipuca) & 0 & 1 & 3 & 3 & - & 7 \\
\hline 23 & Praia do lluminado & 0 & 1 & 1 & 1 & 3 & 6 \\
\hline 24 & Praia do Tiririca & 0 & 2 & 2 & 2 & 3 & 9 \\
\hline 25 & Praia da Raimundona & 0 & 3 & 1 & 0 & - & 4 \\
\hline 26 & Praia da Raimundinha & 0 & 3 & 1 & 0 & - & 4 \\
\hline 27 & Praia do Sobrado & 0 & 2 & 2 & 1 & 3 & 8 \\
\hline 28 & Praia do Canauiri & 0 & 1 & 2 & 2 & - & 5 \\
\hline 29 & Prainha do Jacareubá & 0 & 1 & 2 & 1 & - & 4 \\
\hline 30 & Praia do Jauari & 0 & 3 & 0 & 1 & 2 & 6 \\
\hline 31 & Praia do Gaivota & 0 & 2 & 0 & 2 & 1 & 5 \\
\hline 32 & Praia do Aracari & 0 & 1 & 2 & 1 & 2 & 6 \\
\hline 33 & Praia do Baranoa & 0 & 2 & 2 & 2 & 1 & 7 \\
\hline 34 & Praia da Fortuna & 0 & 3 & 1 & 0 & - & 4 \\
\hline 35 & $\begin{array}{l}\text { Corredeira/Cachoeira Rio Bariaú } \\
\text { (na cheia) }\end{array}$ & 0 & 2 & 1 & 1 & - & 4 \\
\hline 36 & $\begin{array}{l}\text { Corredeira/Cachoeira Rio Puduari } \\
\text { (na seca) }\end{array}$ & 0 & 2 & 1 & 1 & 1 & 5 \\
\hline 37 & Flutuante dos Botos & 2 & 1 & 2 & 3 & 3 & 11 \\
\hline 38 & Base 1 do ICMBio & 2 & 3 & 2 & 2 & - & 9 \\
\hline 39 & Base 2 do ICMBio & 2 & 2 & 2 & 2 & - & 8 \\
\hline 40 & $\begin{array}{l}\text { Comunidade Ribeirinha Santo } \\
\text { Antônio }\end{array}$ & 2 & 2 & 2 & 2 & 3 & 11 \\
\hline 41 & Comunidade Ribeirinha Tiririca & 2 & 2 & 2 & 2 & 3 & 11 \\
\hline 42 & Ruínas de Airão Velho & 0 & 3 & 1 & 2 & - & 6 \\
\hline 43 & Gruta do Madadá & 0 & 3 & 1 & 2 & - & 6 \\
\hline
\end{tabular}

Fonte: Pesquisa de campo, 2018.

Source: Field research, 2018. 


\section{- Observação}

Nos meses de maio, outubro e novembro de 2018, foram realizadas 8 visitas aos atrativos do Parque Nacional de Anavilhanas, com duração média de 2 h e 30 mim cada visita. Para se chegar aos atrativos foi utilizada como meio de transporte uma lancha rápida denominada na região de voadeira, e as visitas foram guiadas por piloteiros ${ }^{1}$ da Associação ATUNA.

Todas as observações feitas durante as visitas foram registradas. Quanto às observações assistemáticas, foram registrados aspectos da fauna e flora. Por outro lado, a observação sistemática possibilitou o registro de elementos significativos dos atrativos, como observações sobre o acesso, a infraestrutura e o estado de conservação.

$\mathrm{Na}$ pesquisa de campo foram visitados 16 atrativos do Parque Nacional de Anavilhanas, relacionados no Quadro 6:

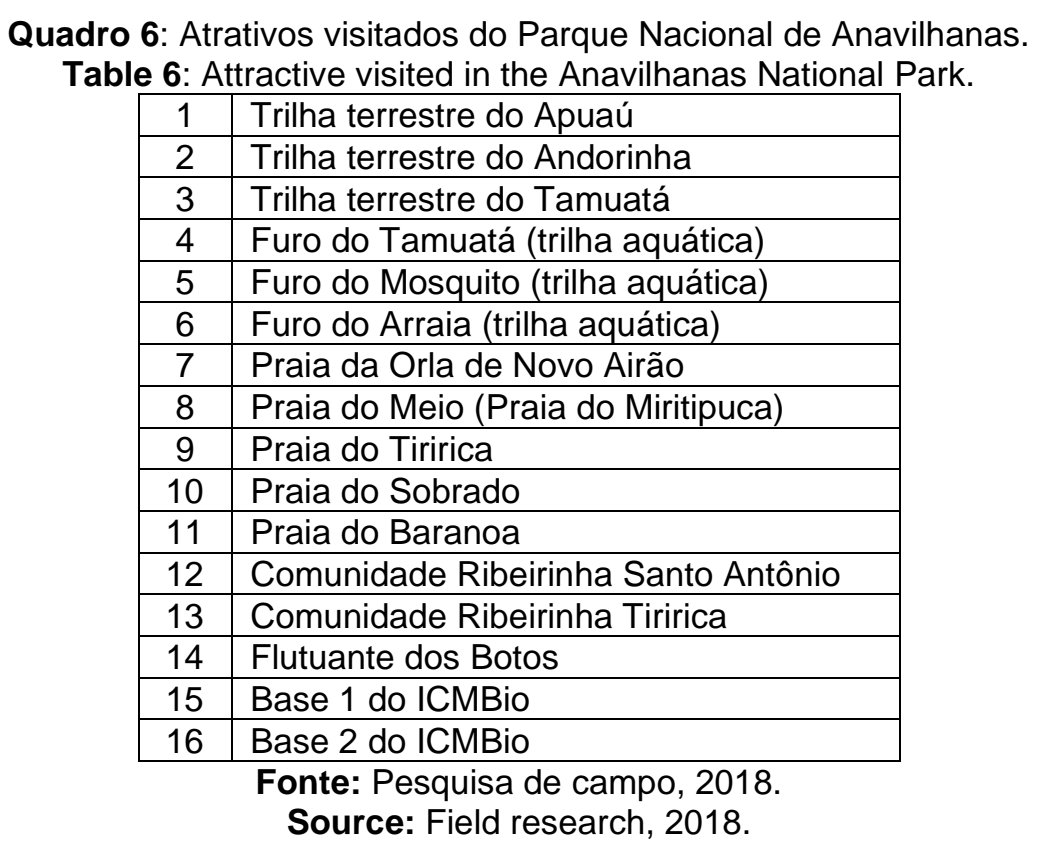

\section{Apresentação dos resultados do ranking de avaliação dos atrativos}

A partir da análise dos pontos obtidos na hierarquização dos atrativos do Parque (Quadro 5), pode-se construir o ranking dos atrativos do Parque Nacional de Anavilhanas, em uma ordem numérica de acordo com pontuação recebida na avaliação dos atrativos.

O ranking dos atrativos do Parque são apresentadas no Quadro 7: 
Quadro 7: Ranking dos atrativos do Parque Nacional de Anavilhanas.

Table 7: Ranking of the attractive of the Anavilhanas National Park.

\begin{tabular}{|c|c|c|}
\hline $\begin{array}{c}\text { ATRATIVOS DO PARQUE NACIONAL DE } \\
\text { ANAVILHANAS }\end{array}$ & $\begin{array}{l}\text { Total } \\
\text { de Pontos }\end{array}$ & Ranking \\
\hline Flutuante dos Botos & 11 & 1 \\
\hline Comunidade Ribeirinha Santo Antônio & 11 & 1 \\
\hline Comunidade Ribeirinha Tiririca & 11 & 1 \\
\hline Base 1 do ICMBio & 9 & 2 \\
\hline Praia do Tiririca & 9 & 2 \\
\hline Furo do Arraia (trilha aquática) & 8 & 3 \\
\hline Praia do Sobrado & 8 & 3 \\
\hline Base 2 do ICMBio & 8 & 3 \\
\hline Praia da Orla de Novo Airão & 8 & 3 \\
\hline Praia do Meio (praia do Miritipuca) & 7 & 4 \\
\hline Praia do Baranoa & 7 & 4 \\
\hline Trilha terrestre do Apuaú & 7 & 4 \\
\hline Trilha terrestre do Andorinha & 7 & 4 \\
\hline Trilha terrestre do Tamuatá & 7 & 4 \\
\hline Furo do Andorinha (trilha aquática) & 7 & 4 \\
\hline Furo do Tamuatá (trilha aquática) & 7 & 4 \\
\hline Furo do Mosquito (trilha aquática) & 7 & 4 \\
\hline Lago do Canauiri (trilha aquática) & 7 & 4 \\
\hline Paraná do Pavão Comprido (trilha aquática) & 7 & 4 \\
\hline Furo do Apuí (trilha aquática) & 7 & 4 \\
\hline Furo do Apacuzinho (trilha aquática) & 7 & 4 \\
\hline Praia do Folharal & 6 & 5 \\
\hline Praia do Saracá & 6 & 5 \\
\hline Praia do lluminado & 6 & 5 \\
\hline Praia do Aracari & 6 & 5 \\
\hline Praia do Jauari & 6 & 5 \\
\hline Lago do Marajá (trilha aquática) & 6 & 5 \\
\hline Trilha terrestre do Apacuzinho & 6 & 5 \\
\hline Trilha terrestre do Apacuzinho & 6 & 5 \\
\hline Ruínas de Airão Velho & 6 & 5 \\
\hline Gruta do Madadá & 6 & 5 \\
\hline Praia do Camaleão & 5 & 6 \\
\hline Praia do Canauiri & 5 & 6 \\
\hline Praia do Gaivota & 5 & 6 \\
\hline Corredeira/Cachoeira Rio Puduari & 5 & 6 \\
\hline Prainha do Jacareubá & 4 & 7 \\
\hline Corredeira/Cachoeira Rio Bariaú & 4 & 7 \\
\hline Praia da Fortuna & 4 & 7 \\
\hline Praia da Raimundona & 4 & 7 \\
\hline Praia da Raimundinha & 4 & 7 \\
\hline Trilha terrestre do Miritipuca & 4 & 7 \\
\hline Trilha terrestre do Barro Branco & 4 & 7 \\
\hline Trilha terrestre do Bariaú & 3 & 8 \\
\hline
\end{tabular}

Fonte: Pesquisa de campo, 2018. Source: Field research, 2018.

Esta pesquisa buscou subsídios que pudessem ajudar no planejamento turístico a partir do resultado da hierarquização dos atrativos naturais do Parque Nacional de Anavilhanas. Os resultados foram avaliados de acordo com critérios como infraestrutura, estado de conservação, acesso, grau de uso e apoio local comunitário, passando assim a serem analisados separadamente: 


\section{Infraestrutura}

De acordo com o MTur (2007, p. 50) "a infraestrutura de apoio ao turismo é todo o conjunto formado por obras e instalações de estrutura física e de serviços, indispensáveis ao desenvolvimento do turismo e existentes em função dele".

Para Santos (2004), é interessante perceber que alguns destinos de ecoturismo apresentam uma grande carência de infraestrutura sem serem significativamente prejudicados por essa situação.

Convém mencionar que uma infraestrutura básica de transporte (estradas, ferrovias, aeroportos, estacionamento), serviços de utilidade pública (eletricidade, água, comunicações) e outros serviços como saúde e segurança, aliados a uma infraestrutura turística e a potencialidades atrativas aos olhos de consumidores do turismo, podem impulsionar 0 desenvolvimento da atividade em grande parte das localidades (TADINI; MELQUIADES, 2010).

A análise da infraestrutura instalada nos atrativos, levou em consideração que são atrativos naturais em uma área protegida de categoria proteção integral, portanto, possui uma infraestrutura turística diferenciada, com algumas instalações, com poucos serviços de alimentação na sede do município, trilhas manejadas, sistema de comunicação precário e outros.

Como descrito no Quadro 5, nenhum dos atrativos foi hierarquizado em nível 3 (ótimas condições). O resultado mais significativo é que 6 atrativos foram hierarquizados em nível 2, ou seja, apresentam uma infraestrutura que necessita de melhorias. $E$, nenhum dos atrativos foi hierarquizado em nível 1, ou seja, representa que não há infraestrutura em estado precário de conservação.

Nessa dimensão, atrativos que tenham alto grau de interesse, mas condições precárias de acolhida aos visitantes, são prioritários para ações de melhorias de infraestrutura. No caso do ecoturismo, no Parque Nacional de Anavilhanas é importante que sejam agregados novos investimentos a essa infraestrutura básica, com o intuito de prover ao ambiente local condições de receber da melhor forma possível os visitantes no parque. Em termos de sugestão, a implementação de um centro de visitantes, por exemplo, pode fazer a diferença no Parna.

\section{Estado de conservação da paisagem circundante}

O estado de conservação do atrativo turístico diz respeito a sua qualidade como recurso natural, quanto mais conservado, mais importante para determinadas modalidades de turismo (ecoturismo e turismo de aventura, por exemplo). A hierarquização pode subsidiar a identificação dos atrativos em processo de degradação e servir de alerta para intervenções mitigadoras de impactos negativos (OLIVEIRA, 2011).

Doze (12) atrativos foram hierarquizados em nível 3 (ótimo estado de conservação), isso se deve ao fato de que esses atrativos são pouco visitados, assim encontram-se em estado de conservação caracterizado 
como ótimo, ou seja, com o mínimo de alteração por ação antrópica. A maioria dos atrativos (16) foram hierarquizados em nível 2 (bom estado de conservação). Treze (13) atrativos foram considerados em estado de conservação regular.

Apenas dois (2) atrativos foram avaliados como em péssimo estado de conservação, que são: a Praia do Saracá e a Praia da Orla de Novo Airão, devido a expressiva quantidade de resíduos sólidos, materiais descartados inadequadamente e o desrespeito às placas de sinalização. As agressões ao patrimônio natural são atribuídas aos moradores e visitantes frequentadores dessas praias, bem como, faz-se o alerta ao poder público no que diz respeito à sensibilização para a conservação desses espaços de lazer e turismo.

Para Nóbrega e Dantas (2014), o ecoturismo é um forte aliado a conservação de áreas naturais, e uma grande oportunidade potencial para desenvolver tal atividade em áreas protegidas. O Parque, pela importância de seus atrativos naturais, poderia contar com uma maior interação entre a comunidade local e o poder público, enfocando o respeito à natureza em virtude de sua relação intrínseca, e a busca pela conservação, o que pode se tornar peça fundamental para o desenvolvimento local e regional.

\section{Acesso}

Quanto mais acessível um atrativo, maior a probabilidade de integrá-lo aos programas turísticos. "Uma localidade, por exemplo, mesmo contando com atrativos (e infraestrutura) turísticos, pode ter sua comercialização como destino turístico inviabilizada pela precariedade de acesso" (OLIVEIRA, 2011, p. 80).

Para Silva (2009), os principais determinantes da acessibilidade de um atrativo turístico são: a acessibilidade física, a localização geográfica, a facilidade de acesso e a sinalização indicativa. Esses itens podem facilitar ou dificultar a apropriação do atrativo, influenciando diretamente a percepção dos turistas relativamente ao atrativo em questão.

Quatorze (14) atrativos foram hierarquizados em nível 3 (ótimas condições de acesso). Um resultado significativo foi a indicação que a maioria dos atrativos naturais (15) foram hierarquizados em nível 2 , ou seja, representa que o acesso aos atrativos necessita de melhorias. Onze (11) atrativos foram hierarquizados em nível 1, avaliados como apresentando acesso em estado precário e deficiente.

Apenas três (3) atrativos foram classificados em nível 0, ou seja, com acesso inexistente, que são: trilha terrestre do Bariaú, Praia do Jauari e Praia da Gaivota. Para análise desse critério buscou-se verificar a existência e condições de uso das vias de acesso ao atrativo. Foram levados em consideração a distância e o custo para chegar até o atrativo. 


\section{Grau de uso atual}

Para Oliveira (2011), essa dimensão analisa a situação efetiva do fluxo turístico em cada atrativo. Isso implica afirmar que o atrativo que possui um alto grau de uso apresenta uma utilização turística efetiva. Há necessidade do poder público e da gestão do Parna ficarem atentos a esses atrativos, pois é muito comum que áreas naturais que possuam um fluxo turístico intenso sejam degradas pelo alto nível de utilização.

Dez (10) atrativos possuem a mais alta hierarquização (em nível 3) quanto à intensidade do fluxo turístico, que são: a Praia da Orla de Novo Airão, Praia do Meio (Praia do Miritipuca), o Flutuante dos Botos, Furo do Andorinha (trilha aquática), Furo do Tamuatá (trilha aquática), Furo do Mosquito (trilha aquática), Lago do Canauiri (trilha aquática), Paraná do Pavão Comprido (trilha aquática), Furo do Arraia (trilha aquática) e o Furo do Apuí (trilha aquática).

Quinze (15) atrativos naturais foram hierarquizados em nível 2 (nível médio de intensidade do fluxo turístico), dez (10) foram hierarquizados em nível 1 (nível baixo de intensidade do fluxo turístico), e oito (8) atrativos apresentaram fluxo turístico insignificante, ou seja, nível 0 , conforme mostra o Quadro 5.

\section{Apoio Local Comunitário}

O envolvimento das comunidades tem importante papel nas práticas turísticas, podendo ser os melhores elos na interação com o visitante. Os habitantes e nativos das localidades turísticas não devem ter no turismo uma ameaça destrutiva de suas identidades culturais e sítios simbólicos de pertencimento (ZAOUAL, 2003).

Nesse critério avaliado, seis (6) dos atrativos obtiveram hierarquização em nível 3 (o mais alto). Quatro (4) dos atrativos foram classificados em nível de hierarquização correspondente a 2, ou seja, apoiados por uma pequena parte da comunidade e; quatro (4) atrativos em nível correspondente a 1, conforme mostra o Quadro 5.

Ressalta-se que, na maioria dos atrativos do Parque (29), o apoio local comunitário é inexistente. Por se tratar de um arquipélago, e, também contar com floresta de igapó, as comunidades localizam-se no entorno do Parque e não nos seus limites. No total são 50 comunidades dispostas entre as margens direita e esquerda do Rio Negro.

Para que a relação entre a sociedade e a natureza seja estabelecida de maneira efetiva, o turismo tem sido empregado como foco central para resgate e manutenção social, cultural e ambiental de certas localidades, podendo ser agente influenciador na proteção do meio ambiente (ZAMIGNAN; SAMPAIO, 2010).

Esse é um importante indicativo da fragilidade do apoio comunitário às práticas ecoturísticas no Parque Nacional de Anavilhanas, um quesito de importância estratégica para a implantação de uma política de promoção do turismo, que possa apontar resultados positivos para o desenvolvimento ambiental e socioeconômico local. 


\section{Atrativos para inclusão em roteiros de visitação}

Foi apresentado o ranking dos atrativos do Parque (Quadro 7), para que estes possam compor possíveis roteiros de visitação. Como sugestão, foram elaborados dois roteiros, para passeios de duração de um dia e, de acordo com as épocas do ano (cheia e vazante do Rio Negro). Visto que estas influenciam a visitação a alguns atrativos do Parque, como, por exemplo, as praias do arquipélago, que só podem ser visitadas no período da vazante, e a floresta de igapó, no período da cheia do rio.

Seguem abaixo as sugestões de possíveis roteiros de visitação aos atrativos do Parque Nacional de Anavilhanas:

\section{Atrativos sugeridos para inclusão no roteiro 1 (período da vazante):}

Os visitantes podem iniciar o passeio pelo Parque conhecendo 0 Flutuante dos Botos, onde podem realizar as atividades de interação com botos cor de rosa (Inia geoffrensis). Em seguida, os visitantes podem deslocar-se de voadeira ${ }^{2}$ para conhecer as trilhas terrestres, como a do Andorinha ou a do Tamuatá, para fazer observação de fauna e flora. Após, podem seguir de voadeira, para visitar a Base 1 do ICMBio, onde podem fazer atividade de observação de jacarés. Ainda podem ir de voadeira até as comunidades ribeirinhas Tiririca e Santo Antônio para conhecer seus costumes, artesanato, fauna e flora. Além disso, os visitantes podem finalizar conhecendo as praias de água doce do arquipélago de Anavilhanas, como a Praia do Tiririca, ou escolher outras praias como a: Praia do Meio, Praia do Baranoa ou a Praia do Sobrado, para desfrutar do banho de rio, podendo ainda pernoitar na praia.

\section{Atrativos sugeridos para inclusão no roteiro 2 (período da cheia):}

Os visitantes podem iniciar o passeio pelo Parque deslocando-se de voadeira para conhecer a Base 2 do ICMBio, onde podem fazer atividade de observação de fauna e flora, bem como, obervar o casal de antas, e aproveitar para conhecer a trilha do Apuaú. Após, podem deslocar-se de voadeira para conhecer as trilhas aquáticas, como o: Furo do Arraia, Furo do Mosquito, Furo do Tamuatá, Furo do Andorinha ou o Lago do Canauiri, para observação de fauna, flora presentes na floresta de igapó, como também, podem observar as árvores centenárias conhecidas como macucus gigantes (grandes árvores da espécie Aldina heterophylla). É possível, também, os visitantes finalizarem o passeio conhecendo o Flutuante dos Botos, para fazer a atividade de interação com botos cor de rosa (Inia geoffrensis).

\section{Considerações finais}

A metodologia proposta pelo MTur (2007) foi um salto no processo de planejamento, na medida em que proporciona uma análise prévia dos atrativos considerados turísticos e estabelece um ranking, em que se definem prioridades para o desenvolvimento turístico, ajudando na gestão do uso público do Parque. 
A partir desse estudo, pode-se perceber os setores prioritários (Quadro 5), como as trilhas terrestres, trilhas aquáticas e o Flutuante dos Botos, para a implementação e a estruturação de ações que visem melhorias para a atividade ecoturística.

Um centro de visitantes seria uma importante infraestrutura para receber os turistas no Parque, como é citado no próprio Plano de Manejo do Parna (2017). Um centro de visitantes ajudaria a divulgar informações e conhecimento sobre a área protegida. As melhorias na infraestrutura e mais serviços relacionados ao turismo, poderiam atrair por mais dias os visitantes no local.

Nesse contexto de área protegida, a visitação no Parque Nacional de Anavilhanas torna-se importante ferramenta de gestão e conservação da biodiversidade. Mas requer um esforço coletivo por meio do planejamento turístico, que inclui a realização de um inventário e uma análise dos recursos, bem como a mensuração de suas potencialidades, ao gerar uma matriz de avaliação e a hierarquização de seus atrativos. Consequentemente, o planejamento turístico e a hierarquização dos atrativos é o que determina o potencial turístico bem como o fluxo de visitantes.

Ressalta-se nessa pesquisa o entendimento da Organização Mundial do Turismo - OMT (2003) no que tange ao objetivo e planejamento do turismo como um norte de desenvolvimento integrado, controlado e que mantenha seu grau de sustentabilidade ecológica. Nessa perspectiva, a promoção do turismo, articulada a uma estratégia de desenvolvimento sustentável que salvaguarde os recursos naturais e afirme os interesses das populações locais, configura-se como um grande desafio tanto para o poder público como para a iniciativa privada.

\section{Referências}

ALMEIDA, M. V. Matriz de Avaliação do Potencial Turístico de Localidades Receptoras. Turismo em Análise, v.20, n.3, dezembro 2009, pp. 541-561.

BOULLÓN, R. C. Los municípios turísticos. México: Trillas, 1995. 110p. (Trillas Turismo).

BRASIL. Portal do Brasil. 2017. Ministério do Turismo assumirá áreas com potencial turístico. Disponível em: <http://www.brasil.gov.br/turismo/ 2017/05/ministerio-do-turismo-assumira-areas-com-potencial-turistico>. Acesso em: 06 out. 2017.

ICMBio. Instituto Chico Mendes de Conservação da Biodiversidade. 2017. Plano de Manejo do Parque Nacional de Anavilhanas. Disponível em: $<$ http://www.icmbio.gov.br/portal/unidadesdeconservacao/biomasbrasileiros/amazonia/unidades-de-conservacao-amazonia/1977-parna-deanavilhanas >. Acesso em: 06 out. 2017.

IGNARRA, L. R. Fundamentos do turismo 3a edição revista e ampliada. Editora Senac. Rio de Janeiro. Cengage Learning. 2013. 
IGNARRA, L. R. Fundamentos do turismo. 2. ed. São Paulo: Pioneira Thompson Learning, 2003.

INSKEEP, E. Tourism planning: an integrated and sustainable development approach. New York: 1991, John Wiley \& Sons. 508p.

IPE (Instituto de Pesquisas Ecológicas). 2009. Ações no desenvolvimento de iniciativas para o turismo de base comunitária no entorno sul do Parque Nacional de Anavilhanas. Manaus: IPE, 12 p.

LENO CERRO, F. 1993. Técnicas de evaluación del potencial turistico. Madrid: Ministerio de Industria, Comercio y Turismo. 261p. (Serie Libros sobre Turismo, 2).

MTUR. Ministério do Turismo. 2017. Brasil número um em atrativos naturais. Disponível em: <http://www.turismo.gov.br/\%C3\%BAltimasnot\%C3\%ADcias/7848-brasil-o-n\%C3\%BAmero-um-do-mundo-em-atrativosnaturais.html>. Acesso em: 06 out. 2017.

MTUR. Ministério do Turismo. 2007. Roteiros do Brasil: Módulo Operacional 7 (Programa de regionalização do Turismo). Brasília, DF: Ministério do Turismo. Disponível em:<http://www.turismo.gov.br/sites/ default/turismo/o ministerio/publicacoes/downloads publicacoes/modulox20 operacional 7 roteirizacao turistica.pdf >. Acesso em: 06 out. 2017.

NÓBREGA, W. R. M.; DANTAS, Í. V. S. Proposição de roteiros ecoturísticos e de turismo de aventura como alternativa de desenvolvimento no município de Acari (RN). Revista Brasileira de Ecoturismo, São Paulo, v.7, n.3, ago/out 2014, pp.576-601.

OLIVEIRA, I. C. A Hierarquização dos atrativos naturais do município de Presidente Figueiredo (AM). Dissertação (Mestrado em Engenharia de Produção) - Universidade Federal do Rio de Janeiro, 2011. 130 f.

ORGANIZAÇAO MUNDIAL DO TURISMO - OMT. Guia de desenvolvimento do turismo sustentável. Porto Alegre: Bookman, 2003.

PINZAN, E. J. A potencialidade da atividade turística para o desenvolvimento regional. Dissertação (Mestrado) - Departamento de Geografia Humana, Faculdade de Filosofia, Letras e Ciências Humanas, Universidade de São Paulo, 2003. 147p.

RUSCHMANN, D. V. M. Turismo e planejamento sustentável: a proteção do meio ambiente. Campinas, SP: Papirus, 1997, 199p.

SANTOS, G. E. de O. Modelo gravitacional do turismo: proposta teórica e estudo empírico dos fluxos turísticos no Brasil. São Paulo, 2004. Dissertação (Mestrado em Ciências da Comunicação) - Escola de Comunicações e Artes, Universidade de São Paulo, São Paulo, 2004.

SILVA, D. M. Investigação do potencial para o espeleoturismo na região da Serra do luiu - BA. Pesquisas em Turismo e Paisagens Cársticas. Campinas. Sociedade Brasileira de Espeleologia: SeTur/SBE: 2009. 
SIMONETTI, S. R.; SOEIRO, P. W.; LIMA, R. M. Parque Nacional de Anavilhanas - AM: desafios do uso público na Amazônia. Anais do VIII Seminário Brasileiro de Áreas Protegidas e Inclusão Social e III Encontro Latino-Americano de Áreas Protegidas e Inclusão Social, 2017, Niterói. p. 2084-2097.

TADINI, R. F.; MELQUIADES, T. Fundamentos do Turismo. v. 1. Rio de Janeiro: Fundação CECIERJ, 2010. 304p. Disponível em: $<$ https://canalcederi.cecieri.edu.br/012016/5834ca099d14e0f180e0f7c7bbac 715c.pdf>. Acesso em: 20 dez. 2017.

VIDAL, M. D. Turismo interativo com botos (Inia geoffrensis) no Baixo Rio Negro, Amazônia Central. Tese (Doutorado em Biodiversidade e Conservação) - Universidade Federal do Amazonas, Manaus, 2018. 201 p.

VIDAL, M. D.; SANTOS, P. M. C.; OLIVEIRA, C. V.; MELO, L. C. 2013. Perfil e percepção ambiental dos visitantes do flutuante dos botos, Parque Nacional de Anavilhanas, Novo Airão - AM. Revista Brasileira de Pesquisa em Turismo, v. 7, n.3, pp.419-435.

ZAMIGNAN, G., SAMPAIO, C.A.C. Turismo de base comunitária como perspectiva para a preservação da biodiversidade e de modos de vidas de comunidades tradicionais: a experiência da microbacia do Rio Sagrado, Morretes (PR). Anais do V Encontro Nacional da ANPPAS, Florianópolis, SC (2010).

ZAOUAL, H. Globalização e diversidade cultural. Trad. Michel Thiollent. São Paulo: Cortez, 2003.

\section{Notas:}

${ }^{1}$ Os piloteiros são responsáveis por comandar a voadeira.

2 Embarcação movida a motor com estrutura e casco de metal, geralmente alumínio.

Mayara de Araujo Silva: Instituto Nacional de Pesquisas da Amazônia, Manaus, AM, Brasil.

E-mail: mayaradearaujosilva@gmail.com

Link para o currículo Lattes: http://lattes.cnpq.br/9392722404422271

Susy Rodrigues Simonetti: Universidade do Estado do Amazonas, Manaus, AM, Brasil.

E-mail: susysimonetti@hotmail.com

Link para o currículo Lattes: http://lattes.cnpq.br/3413430472638905

Data de submissão: 24 de março de 2019

Data de recebimento de correções: 26 de julho de 2019

Data do aceite: 26 de julho de 2019

Avaliado anonimamente 